\title{
Native Radiocephalic Arteriovenous Fistula Creation in Al - Hussein Teaching Hospital ( 2013-2019 ): Review of 50 cases
}

Assistant Professor Dr. Ahmed Abdulameer Daffar ( M. B. CH. B., F. I. B. M. S. ) * drahmeddaffar1979@gmail.com

Dr. Ali Mohsin Obaid ( M. B. CH. B., F. I. B. M. S. ) **

Dralimohsin1981@gmail.com

Dr. Jalal Jaafar Abdulhussein ( M. B. CH. B., F. I. B. M. S. ) ***

Jalal.alzubaidy2015@gmail.com

\section{Abstract:}

Objective : To present the advantages of native radio-cephalic AVF creation over native brachio-cephalic AVF creation in patients with chronic renal failure and on regular hemo - dialysis.

Patients : This is a retrospective study of 50 patients for whom native radio-cephalic AVF was created in the upper limb under local anesthesia over a period of about seven years ( from $1_{\text {st }}$ of March 2013 till $1_{\text {st }}$ of February 2019 ).

Methods: The case sheets of relevant patients for whom an AVF was created were reviewed to collect information like patient's sex, age, site of AVF, type of anastomosis, etc...

Results : Native radio-cephalic AVF creation was offered for different age groups and for both sexes. Side to side anastomosis was carried out for most patients and the preferred site was just above the wrist joint on the lateral aspect of forearm between the radial artery and a nearby superficial vein which was mostly the cephalic vein or one of it's tributaries. The time of first cannulation after AVF creation was variable depending on several factors. Different complications but no mortality had been recorded perioperatively.

Conclusions : Native radio-cephalic AVF creation is always preferred over native brachio-cephalic AVF creation and every effort was made to search for a suitable distally located superficial vein for the purpose of AVF creation.

The region just above the wrist joint on the lateral aspect of forearm was a suitable site for patients with CKD and those with comorbidities because the proximal locations of AVF creation are associated with more complications than the distal ones. Side to side anastomosis for AVF creation was the procedure of choice and the priority was for the non dominant upper limb if possible.

* Medical College / Thi-Qar University / Iraq

** Al-Hussein Teaching Hospital / Thi-Qar Governorate / Iraq

*** Nasiriyah Cardiac Centre / Thi-Qar Governorate / Iraq 
Thi-Qar Medical Journal (TQMJ):Vol.(17),No.(1),2019

Web Site: https://imed.utq.edu.iq

Email:utjmed@utq.edu.iq

ISSN (Print):1992-92 18, ISSN (Online):1992-92 18

DOI: https://doi.org/10.32792/utq/utjmed/17/1/10/0

\section{$\underline{\text { Introduction }}$}

Chronic kidney disease (CKD), previously termed chronic renal failure, refers to an irreversible deterioration in renal function which usually develops over a period of years.

Initially, it is manifest only as a biochemical abnormality but, eventually,

loss of the excretory, metabolic and endocrine functions of the kidney leads to the clinical symptoms and signs of renal failure, collectively referred to as uraemia.

When death is likely without RRT (CKD stage 5), it is called end-stage renal disease or failure (ESRD or ESRF).

The social and economic consequences of CKD are considerable. In most countries, estimates of the prevalence of CKD stage 3-5 (eGFR < 60) are around $5-7 \%$, mostly affecting people aged 65 years and above.The prevalence of CKD in hypertension, diabetes and vascular disease is substantially higher, and targeted screening for CKD should be considered in these and other high-risk groups. The great majority of patients with earlier CKD (stages 1-3) never develop ESRD, which is fortunate, given the numbers.

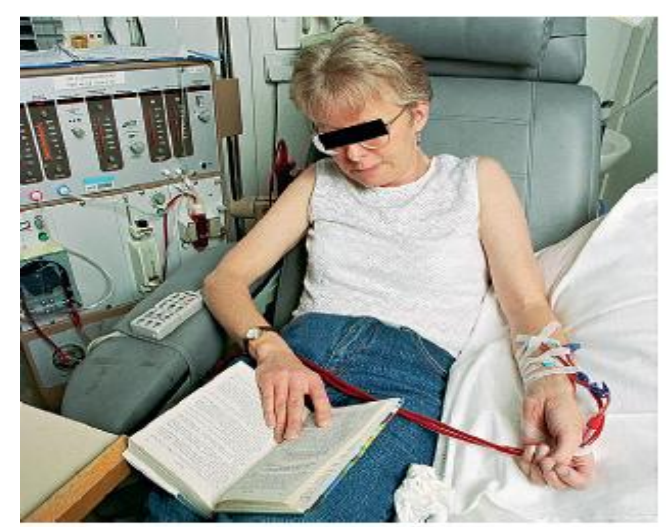

In the picture above is a patient receiving haemodialysis through a forearm subcutaneous (BresciaCimino) fistula. She subsequently received a live related transplant.

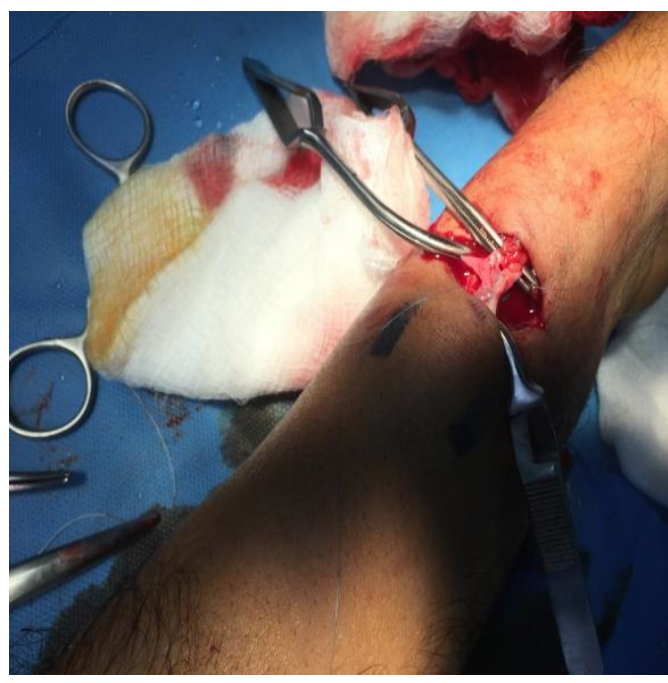

Forearm subcutaneous (BresciaCimino) fistula showing the anastomosis between radial artery and cephalic vein.

\section{Strategies of arteriovenous dialysis access}

With the ever-increasing longevity of the population and physicians' improving ability to treat end-stage renal disease, insertion of vascular access is becoming one of the most common procedures performed by a typical vascular surgeon. The multidisciplinary approach to a patient who may require AV access affords the clinical team the ability to anticipate access need and allow for time for maturation of an autogenous access. The DOQI guidelinesrecommended surgical referral pattern 
should begin when a patient exhibits a creatinine clearance of less than 25 $\mathrm{mL} / \mathrm{min}$ or a serum creatinine of greater than $4 \mathrm{mg} / \mathrm{dL}$ or when $\mathrm{AV}$ access is anticipated within 1 year. ${ }^{[1]}$ This interval allows for evaluation, placement, maturation, and possible revision without the need for catheter insertion in the most ideal circumstance. Although this interval may be ideal, however, it is often not the case, and late presentation to a dialysis unit is associated with increased mortality and increased need for temporary vascular access. ${ }^{[2]}$ Additionally the primary AA requires 3 months to "mature" before cannulation and is the primary access of choice.

\section{Strategies of access location}

The timing of hemodialysis dictates the type of initial access. This decision can be divided into acute, semiacute, and long-term access techniques. Often, as in a patient in whom initial access has failed and who is presently hemodialysis dependent, access is obtained by insertion of a catheter synchronous with a form of long-term access so that the patient may undergo hemodialysis while the access matures.

\section{Acute Access Location and Strategy}

For patients who require immediate dialysis access of less than 3 weeks' duration, a double-lumen cuffed or noncuffed catheter should be inserted into the internal jugular, subclavian or femoral vein. [3] Most importantly, the subclavian position should be avoided if the patient is to be considered for an ipsilateral arm access procedure because the incidence of subclavian stenosis or thrombosis or both increases steadily with the presence of a catheter in this position, rendering the extremity useless for insertion of a permanent access. ${ }^{[4][5][6]}$

\section{Semiacute Access Location and Strategy}

In a situation in which the patient would require hemodialysis for more than 3 weeks' duration, insertion of a cuffed, tunneled, double-lumen catheter should be considered. These catheters also may be employed in situations in which the patient has exhausted all other options for longterm access or in whom hemodialysis is required while an AA matures. The internal jugular vein is preferred because of its proximity to the atrialcaval junction (allowing for better flow), but with the added emphasis of placing the catheter in the right internal jugular vein because this is associated with fewer complications compared with other insertion sites. ${ }^{[7]}[\underline{[8]}$ Insertion into the left internal jugular vein is associated with an increased rate of stenosis and thrombosis and inadequate flow rates. ${ }^{[9]}[10]$

In contrast to a noncuffed temporary bedside catheter, a cuffed catheter must be inserted in a fluoroscopically capable operating room or interventional suite. Although noncuffed catheters can be inserted using Seldinger technique, cuffed catheters are constructed of a softer Silastic material and must be placed by means of a larger "breakaway" introducer catheter. Aside from complications associated with insertion (hemothorax and pneumothorax), the tunneled cuffed catheter can be relied on to function for an average of 6 months, after which infection, fibrin sheath formation, or thrombosis may curtail usage. ${ }^{[11]}$ Using endoluminal 
Web Site: https://imed.utq.edu.iq

Email:utjmed@utq.edu.iq

ISSN (Print):1992-92 18, ISSN (Online):1992-92 18

DOI: https://doi.org/10.32792/utq/utjmed/17/1/10/0

therapy or percutaneous mechanical techniques, Suchoki and colleagues [12] were able to prolong average catheter patency to 12.7 months.

\section{Strategies of location and type of access}

\section{Preoperative Evaluation}

Before consideration of any long-term access procedure, a thorough history and physical examination should be performed. Aspects of prior history, other than typical items of interest to the surgeon, should include type and location of any indwelling catheters, even subsequent to removal, given the association with deep vein stenosis ${ }^{[13]}$. The surgeon should also evaluate the patient for congestive heart failure, D.M and should make note of the patient's dominant extremity and whether the extremity has endured penetrating trauma or recent catheter insertion. ${ }^{[14][15]}$

The assessment of the vasculature in the chosen limb should include palpation of pulses at all levels and an Allen test, which, if abnormal, may contraindicate a distal AA. The blood pressure of both upper extremities should be measured and compared for difference, indicating more proximal arterial disease. Special attention is given to the status and adequacy of the veins of the hand, wrist, forearm, elbow, and upper arm. A vein is considered adequate if it is visible through the skin with or without a tourniquet applied. In instances in which a prior access has failed, imaging of the arterial or venous system may be necessary to plan a procedure adequately. The use of venous duplex examination may suffice as long as the surgeon recognizes the limitations of the study to detect proximal deep vein stenoses ${ }^{[16]}$ and the technician dependency. ${ }^{[17]}[118]$ An added advantage of injection venography is the ability to correct underlying lesions that are amenable to such therapy before the access placement. ${ }^{[19]}$ Lesions that cannot be corrected should disqualify the limb as a potential access site. Preference is given to the nondominant arm over the dominant arm, followed by distal location before proximal location.

TABLE 117-1 -- Indications of Venous Imaging Before Access Insertion

Edema in the extremity in which an access is planned

Collateral vein development in any planned access site

Differential extremity size of the considered limb

Current or previous transvenous catheter, of any type, in the ipsilateral limb

Previous arm, neck, or chest trauma or surgery in venous drainage of planned access site

Multiple previous accesses in the ipsilateral extremity

Adapted from NKF-K/DOQI Clinical practice guidelines for vascular access: Update 2000. Am J Kidney Dis 37:S137-S181, 2001.

\section{Strategies of autogenous access creation}

The first autogenous access creation for the purposes of hemodialysis access was the Brescia-Cimino radiocephalic direct wrist access in 1966. ${ }^{[20]}$ Overall, the AA affords a superior patency of $75 \%$ at 4 years, yet has a higher rate of early failure. [21] Although the AA carries a better patency rate when established, it must be allowed to mature for 
approximately 6 to 8 weeks, occasionally longer, and may require the patient to undergo insertion of a percutaneous catheter for hemodialysis if referral for creation of the fistula was not timely. In addition, results of $\mathrm{AA}$ creation have been associated with poor results in certain subsets of patients, such as diabetics or women who underwent forearm AA or in older patients. ${ }^{[22]}$ The AA carries a much lower rate of complications compared with the PA, ${ }^{[23]}$ [24] [25] however, and adequate flows are more easily attainable.

\section{Autogenous Posterior Radial Branch-Cephalic Direct Access}

The autogenous posterior radial branch-cephalic direct access (snuffbox fistula) is to date the most distal AA described. It consists of an end-to-side anastomosis between the distal cephalic vein and the thenar branch of the radial artery, the pulse of which is usually palpable through the floor of the anatomic snuffbox, created through one incision.

\section{Autogenous Radial-Cephalic Direct Wrist Access}

The autogenous radial-cephalic direct wrist access (Brescia-Cimino fistula) is perhaps the "gold standard" of AA creation. First described in 1966, this access also has been called the Cimino fistula or the wrist fistula. It's construction consists of anastomosis between the cephalic vein at the wrist to the radial artery.

Results of the Cimino fistula have been generally good. Similar to most experiences with AA, most failures occur within the first 12 months, beyond which the patency rates are excellent.

\section{Radial-Basilic Forearm Transposition}

As an alternative before the use of a more proximal vein in a patient who has failed or is not a candidate for Cimino fistula, transposition of the basilic vein of the forearm to a ventral position with end-to-side radial-basilic anastomosis is a viable option described first by Silva and colleagues, ${ }^{[26]}$ the results of radial/ulnar-basilic forearm transposition have been similar to that of other forearm AA.

\section{Brachial-Cephalic Direct Elbow Access}

Anastomosis of the antecubital veins with the brachial artery can be accomplished with good result. Termed brachial-cephalic direct elbow access (cephalic turndown or brachialcephalic fistula), this type of AA, which involves anastomosis between the cephalic or basilic vein and the brachial artery, has been suggested in patients with diabetes for its superior flow and maturation rate. Despite favorable results, the fistula has a higher incidence of steal, especially with long donor arteriotomies. The brachial-cephalic fistula also eliminates the remainder of the forearm as a possible site of future access.

\section{Autogenous Brachial-Basilic Upper Arm Transposition}

Usually considered the last routine AA alternative of the upper limb, the autogenous brachial-basilic upper arm transposition (basilic transposition) 
ISSN (Print):1992-92 18, ISSN (Online):1992-92 18

DOI: https://doi.org/10.32792/utq/utjmed/17/1/10/0

was first described by Dagher and colleagues in 1976. ${ }^{[27]}$ The procedure involves mobilization, distal division, and superficial tunneling and transposition of the basilic vein with distal end-to-side anastomosis with the brachial artery.

\section{Lower Extremity Autogenous Access}

If all upper extremity dialysis access options have been exhausted, the surgeon may consider the use of the lower extremity for insertion of an AA. Use of a loop of saphenous vein and transposition of the superficial femoral vein has been described; results have been mixed. Lower extremity AA is more likely to fail to mature, to subject the patient to steal syndrome, and to experience thrombosis earlier than upper extremity AA and probably PA as well, in addition to the added morbidity of saphenous harvest and

groin wound infection.

\section{Aim of study}

To present the advantages of native arteriovenous fistula creation in comparison with native brachiocephalic AVF creation in patients with chronic renal failure and on regular hemo - dialysis or those with impending end stage renal disease and that searching for a suitable superficial vein for this purpose is mandatory.

\section{Patients and Methods}

This is a retrospective study of 50 patients suffering from chronic renal failure for different causes ( 26 females \& 24 males ) for whom arteriovenous fistulae were created under local anaesthesia from the first of March 2013 till the first of February 2019 in Al - Hussein Teaching Hospital in Thi - Qar governorate.

On admission, a quick but informative history was taken from every patient including age, sex, onset of chronic renal failure, the site of previous double lumen catheters and number of dialysis sessions. Baseline data included patient demographics, presence of comorbid diseases including $\mathrm{CHF}$, hypertension, diabetes mellitus.

Clinical judgment and physical examination were used for selection of patients for native fistula placement.The investigations which were needed before surgery included virology screening for hepatitis $\mathrm{B}$, hepatitis $\mathrm{C}$ and HIV and other simple investigations including $\mathrm{PCV}$, random blood sugar, ECG, chest $\mathrm{x}$ - ray. Preoperative arterial and venous mapping of the upper extremities by Doppler ultrasound was not obtained prior to venous access creation and venography for preoperative evaluation of upper extremity veins was not used.

For native fistula placement the radial artery and nearby superficial vein were exposed using the same incision.

Veins too distant from arterial inflow for standard arteriovenous fistula creation were mobilized and transposed to allow fistula creation. The vein was anastomosed to the artery in side to side fashion. In all our patients, no synthetic material was used.

Surgery was done under local anaesthesia using Xylocaine without adrenaline and according to body weight ( $3 \mathrm{mg}$ per $\mathrm{kg}$ ) and a simple 
Web Site: https://imed.utq.edu.iq

Email:utjmed@utq.edu.iq

ISSN (Print):1992-92 18, ISSN (Online):1992-92 18

DOI: https://doi.org/10.32792/utq/utjmed/17/1/10/0

tube drain was inserted at the end of

of the arteriovenous fistula and to operation to prevent the development of hematoma and/or seroma and the patient is admitted into the surgical ward of $\mathrm{Al}-$ Hussein Teaching Hospital for at least 24 hours postoperatively on anticoagulant and antibiotics. The purpose of admission was to detect \& treat any serious bleeding from the site of anastomosis ensure that the patient takes injectable anticoagulant and antibiotics immediately after surgery. Then follow up continues on outpatient basis for several weeks to several months to detect \& treat complications of AVF creation as early as possible and determine the appropriate time at which the AVF becomes ready for use.

\section{$\underline{\text { Results }}$}

Fig. (1). The number of females ( 26 patients ) was slightly higher than males ( 24 patients ).

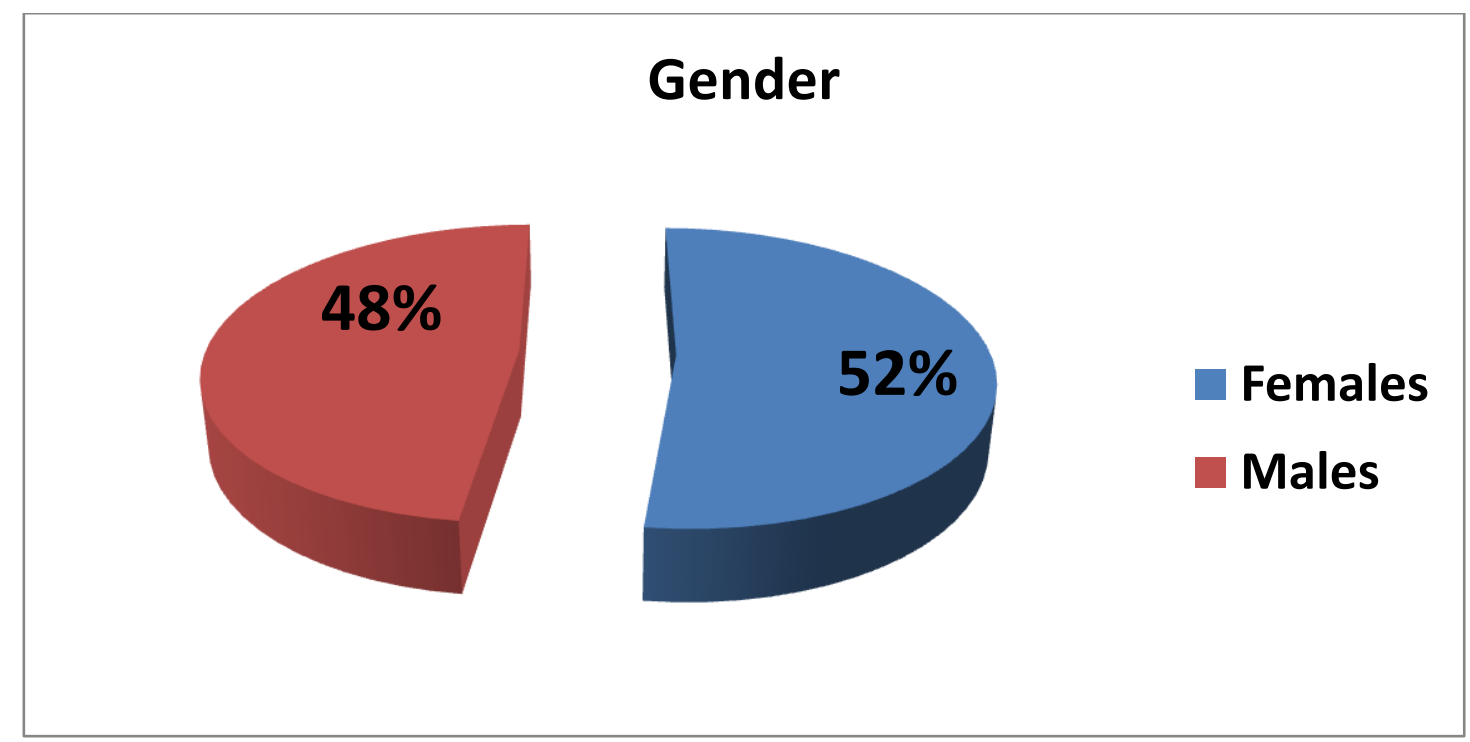

Table (1). The youngest patient in this study was 16 years old and the oldest one was 75 years old with a mean age of ( 42.4 ) years.

\begin{tabular}{|c|c|c|}
\hline Range of age & No. of patients & Percentage \\
\hline$(\mathbf{1 0}-\mathbf{2 0})$ years & 10 & $20 \%$ \\
\hline$(\mathbf{2 0}-\mathbf{3 0})$ years & 20 & $40 \%$ \\
\hline$(\mathbf{3 0}-\mathbf{4 0})$ years & 11 & $22 \%$ \\
\hline$(\mathbf{4 0}-\mathbf{5 0})$ years & 5 & $10 \%$ \\
\hline$(\mathbf{5 0}-\mathbf{6 0})$ years & 3 & $6 \%$ \\
\hline$(\mathbf{7 0}-\mathbf{8 0})$ years & 1 & $2 \%$ \\
\hline Total & 50 & $100 \%$ \\
\hline
\end{tabular}


Web Site: https://imed.utq.edu.iq

Email:utjmed@utq.edu.iq

ISSN (Print):1992-92 18, ISSN (Online):1992-92 18

DOI: https://doi.org/10.32792/utq/utjmed/17/1/10/0

\section{Type of anastomosic technique}

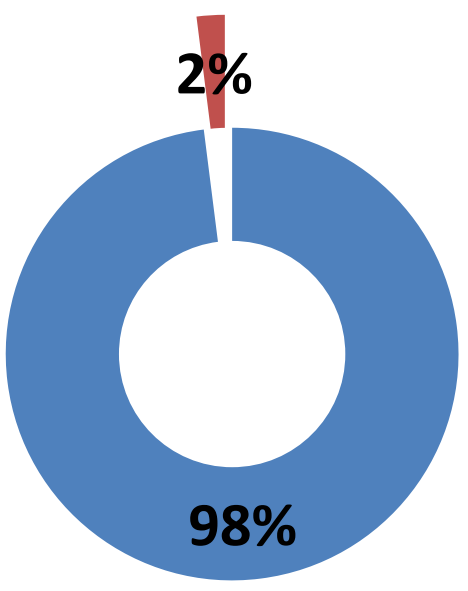

Side to side anastomosis

End to side anastomosis

Fig. (2). Side to side anastomosis was carried out for most patients $98 \%$ ( 49 patients )with only one patient being operated by side to end anastomosis.

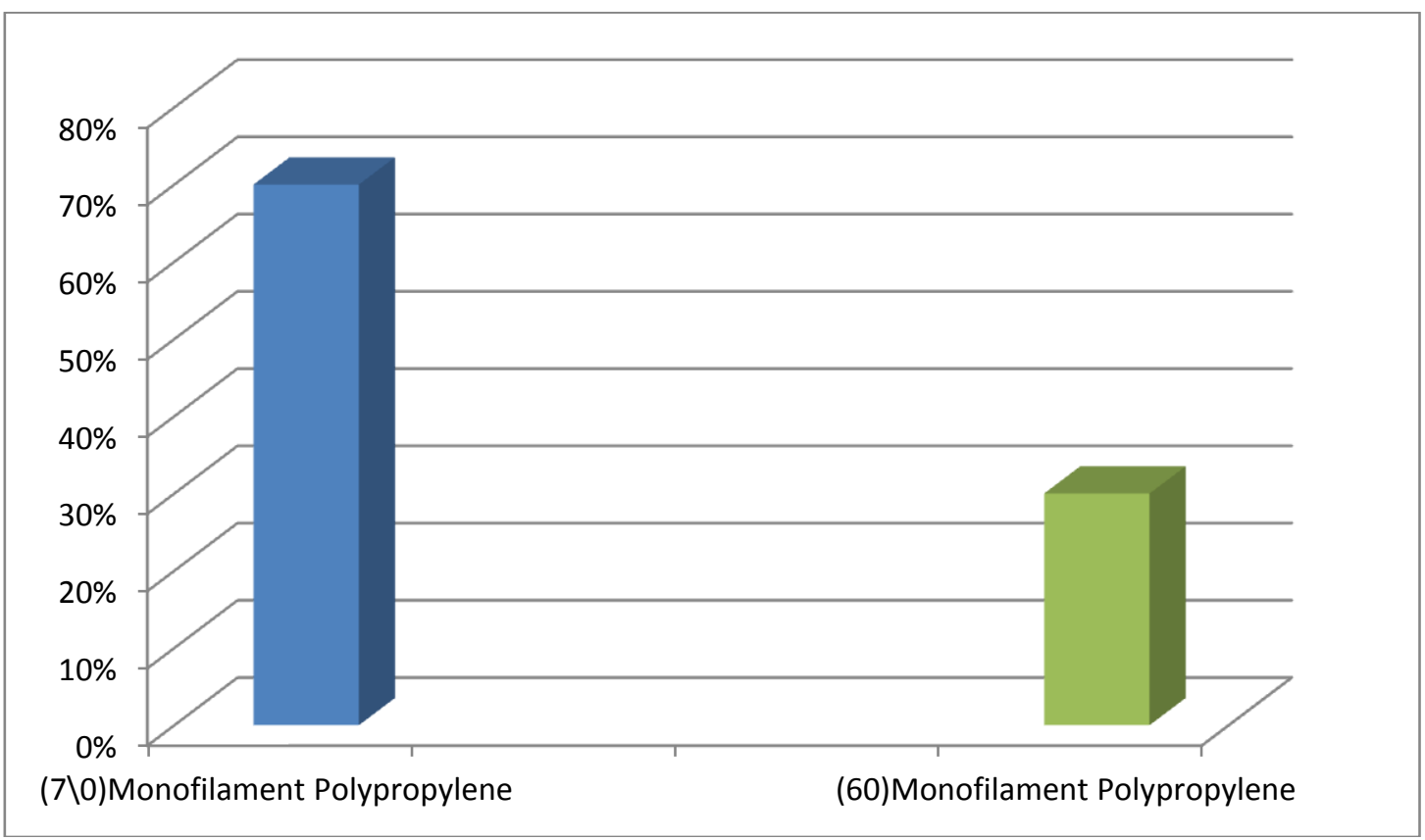


Web Site: https://imed.utq.edu.iq

Email:utjmed@utq.edu.iq

ISSN (Print):1992-92 18, ISSN (Online):1992-92 18

DOI: https://doi.org/10.32792/utq/utjmed/17/1/10/0

Fig. (3). The type of suture material used is always Monofilament Polypropylene ( either 6-0 or 7-0 ). The finer the suture material the smaller the needle and the less trauma of the involved vessels chosen for AVF creation.

Table (2). The non - dominant upper limb is preferred over the dominant upper limb if possible, but this is not always possible.

\begin{tabular}{|c|c|c|}
\hline The upper limb side & No. of patients & Percentage \\
\hline The dominant upper limb & 20 & $40 \%$ \\
\hline The non dominant upper limb & 30 & $60 \%$ \\
\hline Total & 50 & $100 \%$ \\
\hline
\end{tabular}

Table (3). All patients for whom an AVF was created had a double lumen catheter in one of the central veins of their body and the operation is always done on elective basis.

\begin{tabular}{|c|c|c|}
\hline Timing of operation & No. of patients & Percentage \\
\hline Elective basis & 50 & $100 \%$ \\
\hline Urgent basis & Zero & Zero $\%$ \\
\hline Total & 50 & $100 \%$ \\
\hline
\end{tabular}

Table (4). An AVF takes several weeks for maturation after which it becomes ready for use depending on several factors including the site of AVF creation, the size of chosen vein for AVF creation, the presence or absence of stenosis or obstruction of the proximal draining veins, technical causes,

\begin{tabular}{|c|c|c|}
\hline Duration of & No. of patients & Percentage \\
\hline maturation & 10 & $20 \%$ \\
\hline 6 weeks & 10 & $20 \%$ \\
\hline 8 weeeks & 25 & $50 \%$ \\
\hline 10 weeks & 2 & $4 \%$ \\
\hline 16 weeks & 3 & $6 \%$ \\
\hline 20 weeks & 50 & $100 \%$ \\
\hline Total & & \\
\hline
\end{tabular}


Web Site: https://imed.utq.edu.iq

Email:utjmed@utq.edu.iq

ISSN (Print):1992-92 18, ISSN (Online):1992-92 18

DOI: https://doi.org/10.32792/utq/utjmed/17/1/10/0

Table (5). The time interval between the first session of dialysis via a double lumen catheter and the AVF creation procedure is very variable depending on several factors.

\begin{tabular}{|c|c|c|}
\hline $\begin{array}{c}\text { Time interval } \\
\text { between the first } \\
\frac{\text { session of dialysis }}{\text { and the AVF }}\end{array}$ & & Percentage \\
\hline $\begin{array}{c}\text { No. of patients } \\
\text { creation }\end{array}$ & & \\
\hline $\begin{array}{c}\text { Before any session of } \\
\text { dialysis }\end{array}$ & 2 & \\
\hline One week & & \\
\hline Two weeks & 3 & $6 \%$ \\
\hline One month & 5 & $10 \%$ \\
\hline Two months & 15 & $30 \%$ \\
\hline Three months & 10 & $20 \%$ \\
\hline Six months & 10 & $20 \%$ \\
\hline One year & 4 & $8 \%$ \\
\hline Total & 1 & $100 \%$ \\
\hline
\end{tabular}

Table (6). Certain complications had been encountered perioperatively but no mortality due to AVF creation was recorded. The most serious complication was the development of pseudo-aneurysm at the site of AVF. Other complications include seroma, simple hematoma, infection, steal syndrome, thrombosis at the site of AVF, limb swelling, etc....

\begin{tabular}{|c|c|c|c|}
\hline Complication & $\underline{\text { No. of patients }}$ & $\underline{\text { Percentage }}$ & $\frac{\text { Type of }}{\text { treatment }}$ \\
\hline Pseudo-aneurysm & 2 & $4 \%$ & $\begin{array}{l}\mathrm{Re}-\text { exploration } \\
\text { (surgery) }\end{array}$ \\
\hline Seroma & 6 & $12 \%$ & $\begin{array}{l}\text { Conservative } \\
\text { measures }\end{array}$ \\
\hline Simple hematoma & 3 & $6 \%$ & $\begin{array}{c}\text { Conservative } \\
\text { measures }\end{array}$ \\
\hline Infection & 5 & $10 \%$ & $\begin{array}{c}\text { Conservative } \\
\text { measures }\end{array}$ \\
\hline Steal syndrome & 2 & $4 \%$ & $\begin{array}{c}\text { Conservative } \\
\text { measures }\end{array}$ \\
\hline $\begin{array}{c}\text { Thrombosis at the } \\
\text { site of AVF }\end{array}$ & 2 & $4 \%$ & $\begin{array}{c}\text { Creation of another } \\
\text { AVF }\end{array}$ \\
\hline $\begin{array}{l}\text { Transient limb } \\
\text { swelling }\end{array}$ & 8 & $16 \%$ & $\begin{array}{c}\text { Conservative } \\
\text { measures }\end{array}$ \\
\hline $\begin{array}{c}\text { Permanent limb } \\
\text { swelling }\end{array}$ & 2 & $4 \%$ & $\begin{array}{c}\text { Conservative } \\
\text { measures }\end{array}$ \\
\hline Failure rate & 5 & $10 \%$ & Accordingly \\
\hline
\end{tabular}




\section{Discussion}

Since initially described in 1966, Radiocephalic fistula or BresciaCimino fistula is one of the most commonly performed fistulas in the world of arteriovenous access.

$\begin{array}{lrr}\text { National } & \text { Kidney } & \text { Foundation } \\ \text { Department } & \text { Outcomes } & \text { Quality }\end{array}$ Initiative guidelines state that AVF is the optimum method for dialysis access . AVF site should be selected as the non-dominant site for achieving comfort of the patient. Primary vascular access should be started from the distal arm such as Radiocephalic fistula. $^{29}$

The KDOQI recommended order of preference for placement of fistulae in patients with chronic kidney disease should be a forearm (Radiocephalic) primary fistula, an elbow (brachiocephalic) primary fistula, a transposed brachial-basilic vein fistula, followed by arteriovenous graft (AVG) of synthetic or biological material.

Among the most important factors that encouraged us to process this study was the improved survival of CRF patients in the recent years, and the continuous need for functioning vascular accesses over time.

We focused our attention searching for the best way to maintain longterm access with the acceptable complication rate.

In our patients, a native AVF was created at a Radiocephalic position under local anaesthesia, this type of vascular access has few disadvantages
, being superficial, unprotected from damage caused by previous venipuncture, and it's smaller diameter making it susceptible for thrombosis .

On the other hand, the advantages were many :

The vein was superficial so there's no need for mobilization

Procedure technically not demanding

Not time consuming

No need for G/A

No foreign material less risk of infection

\section{Cost effective}

Less risk of ischemia

Preservation of more choices for access in the future

Fifty cases were operated, in a single vascular surgery center. The number considered good when compared with other studies such as Whittaker's (58 cases of which 50 are Radiocephalic AVF), Yuksekdag's (33 cases). ${ }^{[30,31] \text {. }}$

The mean age was 42.4 years which was somewhat less than reported in other similar studies . whittaker ( 60 ) and Yuksekdag (61). This was due to younger ages at presentation of CRF in patients operated at our center .

Male to female ratio was nearly the same, with slight female predominance . This was also 
Web Site: https://imed.utq.edu.iq

Email:utjmed@utq.edu.iq

ISSN (Print):1992-92 18, ISSN (Online):1992-92 18

DOI: https://doi.org/10.32792/utq/utjmed/17/1/10/0

comparable to above mentioned

Primary failure rate $(10 \%)$ was much studies .

The strategy used by us was creation of a native Radiocephalic fistula in all operated cases, with side-side anastomosis in up to $98 \%$ (decreasing shear stress and risk of intimal thickening ) , large arteriotomy with distal vein ligation (allowing higher blood flow to maintain patency and enhance maturation) as at this position, there's low risk of steal and high output failure .

This technique found by O'banion et al to be superior to end-side anastomosis in radiocephalic fistula in terms of early thrombosis , six months primary patency, and cannulation rates. The $2 \%$ cases end-side anastomosis was done due to anatomical causes ( distant vein ). ${ }^{[32]}$

Regarding the site chosen for operation , Radiocephalic fistula was created in $60 \%$ of cases in the non-dominant hand following reported guidelines, whereas in the other $40 \%$, this was not possible due to proximal obstruction , tiny or damaged veins .

Twenty percent of Radiocephalic fistulae created needed 6 weeks to maturate, but the majority $(90 \%)$ took about 10 weeks. The delay occurred mostly in older, obese, and ill patients - This delay was explained by structural venous difference related to age, chronic illness, and poor competence with regular hand exercise less than that stated in the current literature $(15-30 \%)$. although it's well known that failure rates in distal AVF is higher, and attributed to small caliber and low flow rates . again our failure rate supported that published by Whittaker (10\%) . Pramila and Biradar reported failure rates up to $22.8 \%$, and in a study by Gonzalez et al, it was $39 \%$. ${ }^{[33,34] .}$

The most complications were seroma and transient limb swelling, were we use conservative measures, but the most important was pseudoaneurism ( 4\%) and thrombosis (4\%) . those complications were comparable to that reported by Checherita et al. with pseudoaneurism related complications percentage of $7.69 .{ }^{[35]}$

Steal syndrome was slightly higher (4\%) in our study than that reported by Whittaker, (2\%), this brought our attentrion for the need of further color flow Doppler assessment of both radial and ulnal arteries in the future to minimize such complication .

\section{Conclusion}

In conclusion, our study supports the use of native radiocephalic arteriovenous fistula creation in patients with favorable veins configurations at the wrist based on adequate blood flow rates, venous segment dilatation, acceptable primary failure rates, and complication rate equivalent to those of other native fistulas. Based on our findings, we 
ISSN (Print):1992-92 18, ISSN (Online):1992-92 18

DOI: https://doi.org/10.32792/utq/utjmed/17/1/10/0

prefer native AVF before creating AV grafts .

After reviewing guidelines, all randomized controlled trials, metaanalyses, prospective series, reviews, and only retrospective series that were appraised to be important for the respected audience, the region just above the wrist joint on the lateral aspect of forearm was a suitable site for patients with CKD and those with comorbidities because the proximal locations of AVF creation are associated with more complications than the distal ones. Side to side anastomosis for AVF creation was the procedure of choice and the priority was for the non dominant upper limb if possible

The combination of careful preoperative mapping, adherence to strict patient selection criteria, and meticulous surgery likely influenced these outcomes.

\section{Recommendations}

1-Surgeons should follow the clinical guidelines set by KDOQI, and understand the importance of creating an AVF at the most distal part of the non-dominant arm, allowing a more proximal site for a new fistula creation in case of any primary failure or complication.

2-Native AVF creation is always preferred over AVF graft and every effort was made to search for a suitable superficial vein for the purpose of AVF creation.

3-The more distal the location of AVF the more chance to get an access, and the elbow region was a suitable option for elderly patients and those with comorbidities.

4-Acceptable results has been obtained by side to side anastomosis between the artery and nearby superficial vein to create an AVF.

5-Complications could be managed well because of close follow up after surgery of AVF creation.

From the above, and to best of our knowledge, we recommend that a radiocephalic fistula be attempted first, if appropriate, in every patient in need of an AVF.

\section{$\underline{\text { References }}$}

1. NKF-K/DOQI Clinical practice guidelines for vascular access: Update 2000. Am J KidneyDis,37:S137-S181,2001.

2. Chesser AM, Baker LR: Temporary vascular access for first dialysis is common, undesirable and usually avoidable. Clin Nephrol 51:228-232, 1999.

3. Bander SJ, Schwab SJ: Central venous angioaccess for hemodialysis and its $\begin{array}{llll}\text { complications. } & \text { Semin } & \text { Dial } & \text { 5:121-128, }\end{array}$ 
4. Schwab SJ, Quarles LD, Middleton JP, et al: Hemodialysis-associated subclavian $\begin{array}{lllll}\text { vein } & \text { stenosis. } & \text { Kidney }\end{array}$

5. Barrett N, Spencer S, McIvor J, Brown EA: Subclavian stenosis: A major complication of subclavian dialysis catheters. Nephrol Dial Transplant 3:423-425, 1988.

6. Spinowitz BS, Galler M, Golden RA, et al: Subclavian vein stenosis as a complication of subclavian catheterization for hemodialysis. Arch Intern Med 147:305-307,1987.

7. Schillinger F, Schillinger D, Montagnac R, Milcent T: Post catheterisation vein stenosis in haemodialysis: Comparative angiographic study of 50 subclavian and 50 internal jugular accesses. Nephrol Dial Transplant 6:722-724, 1991.

8. Cimochowski GE, Worley E, Rutherford WE, et al: Superiority of the internal jugular over the subclavian access for temporary hemodialysis. Nephron 54:154-161, 1990.

9. Moss AH, Mclaughlin MM, Lempert KD, Holley JL: Use of a silicone catheter with a Dacron cuff for dialysis short-term vascular access. Am J Kidney Dis 12:492498,1988 .

10. DeMeester J, Vanholder R, Ringole S: Factors affecting catheter and technique survival in permanent silicone single lumen dialysis catheters [abstract]. J Am Soc Nephrol,3:361A,1992.

11. Schwab SJ, Buller GL, McCann RL, et al: Prospective evaluation of a Dacron cuffed hemodialysis catheter for prolonged use. Am J Kidney Dis 11:166-169, 1988.

12. Suchoki P, Conlon P, Knelson M, et al: Silastic cuffed catheters for hemodialysis vascular access: Thrombolytic and mechanical correction of HD catheters $\begin{array}{llllll}\text { malfunction. } & \text { Am J Kidney } & \text { Dis 28:379-386, }\end{array}$

13. Trerotola SO: Interventional radiology in central venous stenosis and occlusion. SeminIntervRadiol,11:291-304,1994.

14. Palder SB, Kirkman RL, Whittemore AD, et al: Vascular access for hemodialysis: Patency rates and results of revision. Ann Surg 202:235-239, 1985.

15. Raju S: PTFE grafts for hemodialysis access: Techniques for insertion and management of complications. Ann Surg 206:666-673, 1987.

16. Middleton WD, Picus DD, Marx MV, Melson GL: Color Doppler sonography of hemodialysis vascular access: Comparison with angiography. AJR Am J Roentgenol 152:633-639,1989. 
17. Tordoir JHM, Hoeneveld H, Eikelboom BC, Kitslaar PJEHM: The correlation between clinical and duplex ultrasound parameters and the development of complications in arterio-venous fistulae for hemodialysis. Eur J Vasc Surg 4:179-184, 1990 .

18. Tordoir JHM, De Bruin HG, Hoeneveld H, et al: Duplex ultrasound scanning in the assessment of arteriovenous fistulas created for hemodialysis access: Comparison with digital subtraction angiography. J Vasc Surg 10:122-128, 1989.

19. Glanz S, Bashist B, Gordon DH, et al: Axillary and subclavian vein stenosis: $\begin{array}{llll}\text { Percutaneous } & \text { angioplasty. } & \text { Radiology } & 168: 371-373,\end{array}$

20. Brescia M, Cimino J, Appel K, et al: Chronic hemodialysis using venipuncture and a surgically created arteriovenous fistula. N Engl J Med 275:1089-1092, 1966.

21. Rutherford R (ed): Vascular Surgery, 5th ed. Philadelphia, WB Saunders, 2000.

22. Miller PE, Tolwani A, Luscy CP, et al: Predictors of adequacy of arteriovenous fistulas in hemodialysis patients. Kidney Int 56:275-280, 1999.

23. Palder SB, Kirkman RL, Whittemore AD, et al: Vascular access for hemodialysis: Patency rates and results of revision. Ann Surg 202:235-239, 1985.

24. Kinnaert P, Vereerstraeten P, Toussaint C, Van Geertruyden J: Nine years' experience with internal arteriovenous fistulas for hemodialysis: Study of some factors influencing results. $\mathrm{Br} \quad \mathrm{J}$ Surg 64:242-246, 1977.

25. Kherlakian GM, Roedersheimer LR, Arbaugh JJ, et al: Comparison of autogenous fistula versus expanded polytetrafluoroethylene graft fistula for angioaccess in hemodialysis. Am J Surg 152:238-243, 1986.

26. Silva MB, Hobson RW, Pappas PJ, et al: Vein transposition in the forearm for autogenous hemodialysis access. J Vasc Surg 26:981-988, 1997.

27. Dagher F, Gelber R, Ramos E, et al: The use of basilic vein and brachial artery as an A-V fistula for long term hemodialysis. J Surg Res 20:373-376, 1976.

28. Illig KA, Orloff M, Lyden SP, et al: Transposed saphenous vein arteriovenous fistula revisited: New technology for an old idea. Cardiovasc Surg 10:212-215, 2002.

29. NKF-KDOQI. Clinical practice guidelines for vascular access. Am J Kidney Dis. 2006;48(Suppl 1):S248-S272. [PubMed]

30. Whittaker L, Bakran A. Prevention better than cure. Avoiding steal syndrome with proximal radial or ulnar arteriovenous fistulae. J Vasc Access 2011;12:318-20. 
31. Yuksekdag S, Topcu A, Unal E (2019) A Retrospective Analysis of rteriovenous Fistulas as Hemodialysis Access Surgery in the Perspective of KDOQI (Kidney Disease Outcomes Quality Initiative) Guidelines. Int J Transplant Res Med 5:038. doi.org/10.23937/2572- 4045.1510038

32. O'Banion LA, Van Buren D, Davis JW. Radiocephalic fistulas for hemodialysis: A comparison of techniques. Am Surg. 2015;81:341-4. [PubMed]

33. Pramila DR, Biradar S. A study of arteriovenous fistula failure in haemodialysis patients. Sch J Appl Med Sci. 2014;2:336-9.

34. Gonzalez E, Kashuk JL, Moore EE, Linas S, Sauaia A. Two-stage brachialbasilic transposition fistula provides superior patency rates for dialysis access in a safety-net population. Surgery. 2010;148:687-93. [PMC free article] [PubMed]

35. Checherita IA, TuTa LA, David C, Peride I, Niculae A, Geavlete BF, et al. An overview of permanent vascular access in hemodialyzed patients. Rom J Morphol Embryol. 2015;56:27-31. [PubMed] 


\section{إنشاء الناسور الكعبري - رأسي الابتدائي في مستشفى الحسين التعليمي

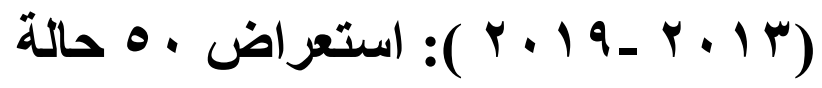 \\ الاكتور علي محسن عبيا الاستاذ المساعد الدكثور احمد عبدالامير دفار الاكتور جلال جعفر عبدالحسين}

\section{الخلاصة}

الإهاف: تقليم ايجابيات إنثاء الناسور الكعبري- رأسي الابتائي ، على انثاء الناسور العضدي - رأسي الابتدائي في المرضى الذين يعانون من الفشل الكلوي المزمن وعلى الغسل الكلوي الكلوي بشكل منتظم.

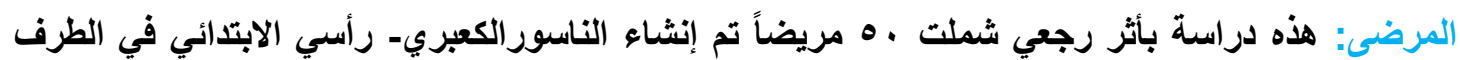

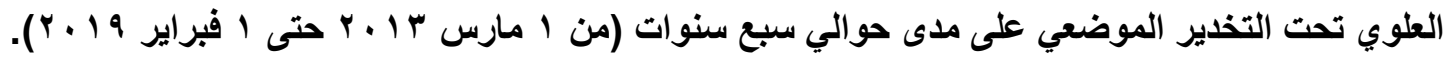

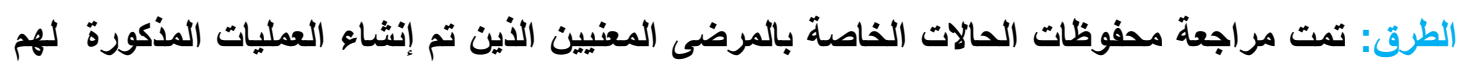

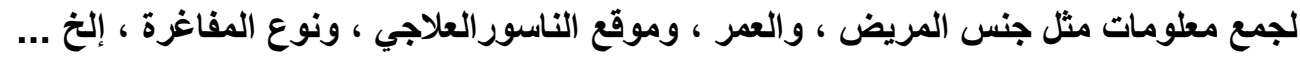

الثتائج: تم تقيم إنثاء إنثاء الناسور الكعبري- رأسي الابتدائي للمجموعات العمرية المختلفة لكلا الجنسين.

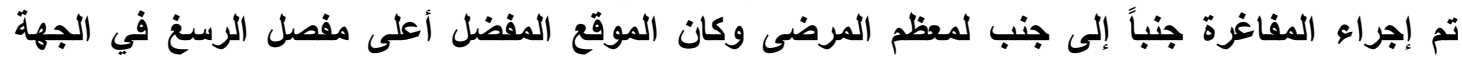

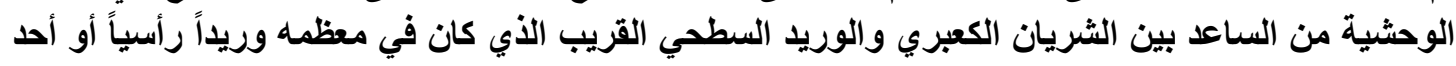

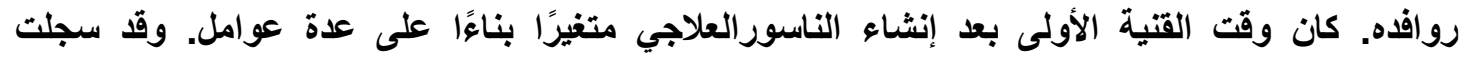
مضاعفات مختلفة ولكن لا وفيات متعلقة بالجراحة.

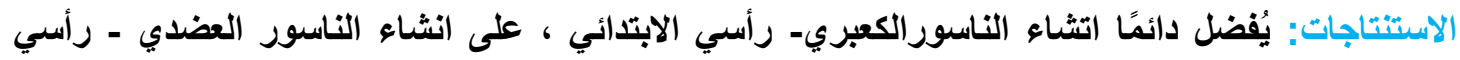

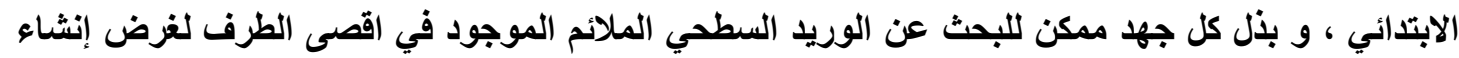

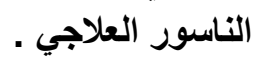

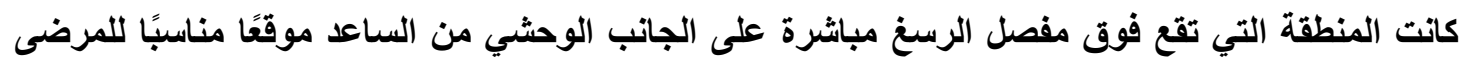

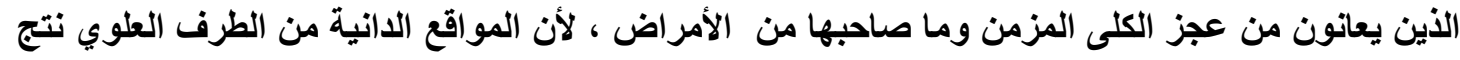

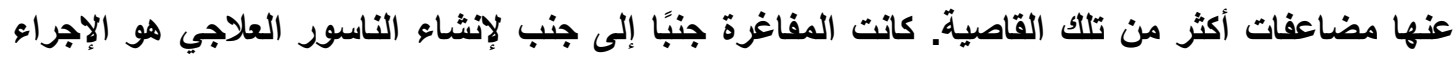
المفضل وكاتت الأولوية للطرف العلوي غير المهيمن إن أمكن. 